Derecho y Realidad

Vol.14 Núm. 27 • Enero Junio de 2016

Págs. 81-102·ISSN:1692-3936

\title{
El non bis in idem en el régimen disciplinario de los abogados al servicio de la administración"
}

\author{
The non bis in idem principle in the disciplinary \\ rules of the attorneys that work with the State
}

\author{
Andrea Carolina Corredor Ramírez**
}

\section{Resumen}

El presente artículo va dirigido a estudiantes y profesionales del derecho, con el fin de construir un ejercicio de la profesión consciente ante las consecuencias que principalmente en materia disciplinaria enmarcan nuestras actuaciones, no solo como abogados, también aquellos que a su vez ostentan la calidad de funcionarios públicos. Se busca establecer si se da la vulneración del principio non bis in idem al aplicar el régimen disciplinario del abogado y el del servidor público a un profesional del derecho que ejerce función pública como apoderado al servicio del Estado, para ello se hace necesario establecer los tipos de vinculación del abogado con la administración, los regímenes

Fecha de aceptación: 16 de julio de 2015

Concepto de recepción: 21 de julio de 2015

Fecha de aprobación: 31 de julio de 2015

\footnotetext{
* El presente artículo fue realizado como resultado de la investigación desarrollada desde el pregrado y finalmente como parte del trabajo monográfico terminado como opción de grado titulado "El non bis in idem en el régimen disciplinario de los abogados a servicio de la administración", teniendo como base una metodología con enfoque analítico y teórico.

** Abogada de la Universidad Pedagógica y Tecnológica de Colombia. Estudiante de la Especialización en Derecho Constitucional de la Universidad Nacional de Colombia. Escribiente en Juzgado Segundo Laboral del Circuito de Yopal Casanare. accorredorr@unal.edu.co
} 
disciplinarios existentes para los abogados y para los servidores públicos y finalmente comparar estos últimos a partir de los presupuestos del principio del non bis in idem para determinar si hay lugar o no a su vulneración.

\section{Palabras clave}

Abogado, servidor público, régimen disciplinario, non bis in idem, administración.

\section{Abstract}

This article is aimed at students and lawyers, in order to do a conscious exercise of the profession in front of the consequences that mainly in disciplinary matters framed our actions, not only as lawyers, but also those who in turn boast the quality of Civil servants. Its purpose is to establish if there is an infringement of the principle of non bis in idem applying the disciplinary rules of the lawyer and the Civil servant to a professional of the law that exerts public function as the attorney to the service of the State, so it is necessary to establish the types of bonding of the attorney with the Administration, disciplinary rules for lawyers and Civil servants and finally compare the latter from the principle of non bis in idem to determine whether or not there is infringement.

\section{Keywords}

lawyer, attorney, Civic servant, disciplinary rule, non bis in idem, Administration. 


\section{Introducción}

El ejercicio profesional del abogado tiene gran importancia en la regulación de las relaciones sociales desde la antigüedad, ya que su natural conocimiento del ordenamiento jurídico le permite mediar en situaciones de conflicto entre los miembros del conglomerado social, ya sean personas naturales o jurídicas de carácter privado o público. Así las cosas, su importancia es tan grande como su responsabilidad, por cuanto su proceder tiene un amplio campo de acción en materia profesional, y es lógico, a puertas de culminar los estudios en derecho, que sea de primera necesidad, entender las consecuencias de un proceder incorrecto en el ejercicio de sus funciones y las responsabilidades en las que puede derivar. Dichas responsabilidades tienen una doble connotación, como es que la administración pública como función (Sánchez, 2001) que busca materializar los fines del Estado colombiano, entre los que se encuentra el interés general, conforme lo demanda la Carta Magna en su articulado, especialmente en los Artículos 2 y 209, vincule a profesionales del derecho para que ejerzan como servidores públicos.

Como quiera, entonces, que la administración se encuentra representada en los servidores públicos que hacen parte de ella, resulta imperioso que sus actuaciones se encuentren sujetas al cabal cumplimiento de los principios que demanda la función pública (Martínez, 2004), tanto en la Constitución, como en el Artículo 3 del Código de Procedimiento Administrativo y de lo Contencioso Administrativo (C.P.A.C.A.), por lo que su actuar contrario a estos lineamientos acarrearía además de las responsabilidades ordinarias de cualquier ciudadano, como puede ser del tipo penal, una de tipo disciplinario.

\section{Metodología}

La metodología utilizada se basa en un enfoque analítico y teórico, pues se realiza a través de la verificación de normas que regulan los regímenes disciplinarios en mención, desarrollo realizado fuera del campo empírico. El método es sistemático, ya que se hace una comparación entre los regímenes disciplinarios y el principio del non bis in idem. El nivel de investigación es de carácter documental, partiendo de fuentes primarias y secundarias como normas, trabajos académicos y jurisprudencia. Como conclusión se busca establecer si a los abogados al servicio de la administración les son aplicables los dos regímenes sin que ello vulnere el principio del non bis in idem. 


\section{El abogado y el servidor público}

Inicialmente, se infiere que todos los servidores públicos son destinatarios del Código Único Disciplinario, donde se establecen las faltas, sanciones y prohibiciones para los servidores públicos. Sin embargo, la situación se torna problemática, cuando los profesionales del derecho ejercen como servidores públicos, ya que estos por su calidad de abogados y por la función social que cumplen (Corte Constitucional, Sentencia C-290 de 2008), también se encuentran como destinatarios en el Código Disciplinario del Abogado, el cual señala faltas y sanciones para quienes ejercen indebidamente la profesión (Corte Constitucional, Sentencia C-899 de 2011).

En este sentido, el régimen disciplinario tiene dos caras para los abogados que ejercen como funcionarios públicos, ya que una falta puede acarrear una doble sanción disciplinaria, en virtud de las Leyes 734 de 2002 y 1123 de 2007, lo cual traería un principio del derecho, el non bis in idem, que indica que una persona no puede ser juzgada dos veces por la misma falta.

\subsection{La profesión del abogado}

El abogado históricamente ha tenido gran importancia dentro del desarrollo de las profesiones liberales, independientemente del sistema legal de cada continente o país, puesto que esta profesión tiende a asociarse con las esferas de poder y decisión pública (Bocanegra, 2012). Lo anterior es sobresaliente en América Latina, ya que los abogados fueron miembros distinguidos de las élites políticas y en gran medida son considerados como constructores de las naciones (Pérez, 2004). Según Horacio Gómez Aristizábal (1974), los primeros abogados se formaron de los colaboradores de los menos aptos para resolver situaciones conflictivas, por lo cual la abogacía puede ser más antigua que su nombre. Así, por ejemplo, en el idioma hebreo no existe la palabra abogado, pero existía una figura denominada "defensores caritativos", que según la Biblia protegían a los pobres, los ignorantes, los huérfanos y las viudas, tal como lo señala el Libro de Isaías y San Juan en el momento en que asume el papel de defensor de la mujer acusada de adulterio. Por otra parte, en los pueblos asirios, caldeos y egipcios, existían sabios u oradores que asumían la defensa verbal o escrita de los intereses públicos y privados (Pacheco, s.f.).

En Roma, la profesión adquiere un nombre propio, ya que la palabra abogado proviene del latín "advocatus", que significa "llamado", que se utilizaba para designar a aquellas personas versadas en las leyes y que se les solicitaba para que los asistiesen ante el pretor como su representante. Allí es donde la profesión adquiere su máxima expresión, en lo que a la antigüedad se refiere, ya que a los abogados se les daba la categoría de sabios o filósofos porque en la filosofía estaban encerrados 
los primeros elementos del derecho (Gómez, 1974). Para ser abogado en Roma, era necesario tener al menos 17 años, haber estudiado Derecho por espacio de 5 años y resultar aprobado en el examen que le hacían al candidato (Pacheco, s.f.). En el Foro romano se gestaron grandes eruditos de la República.

\subsection{El profesional del derecho en la actualidad colombiana}

En Colombia, el Decreto 196 de 1971, "Por el cual se dicta el estatuto del ejercicio de la abogacía", define la abogacía como una función social que busca coadyuvar con las autoridades al perfeccionamiento y conservación del orden jurídico del país y en la realización de una recta y cumplida administración de justicia (Artículo $1^{\circ}$ del Decreto 196 de 1971). Esta misma norma señala que la misión principal del abogado colombiano será defender la justicia, los derechos de la sociedad y de los particulares, así como asesorar y asistir a las personas en la ordenación y desenvolvimiento de sus relaciones jurídicas. Esto último se refiere a que el abogado no solo aparece con ocasión de los pleitos surgidos entre las personas, sino que además ayuda a las personas a organizarse en diferentes aspectos de la vida, como por ejemplo en la celebración de negocios jurídicos.

\section{La abogacía en el servicio público}

\subsection{La administración pública}

La palabra administración es conocida de manera general entre las personas del común, como un término polisémico que denota, tal como lo han señalado tratadistas como Jean Rivero (1984) y Georges Vedel (1980), dos acepciones, una en sentido material o funcional y otra en sentido orgánico. En cuanto al sentido material o funcional, el término refiere a la actividad consistente en manejar una entidad, negocio o empresa (Rodríguez, 2007) y en el sentido orgánico indica los órganos o personas que manejan. De esta manera, la administración, ya en la esfera pública, es el conjunto de actividades, instituciones y personas determinadas al manejo del Estado, lo cual hace pensar en el Estado como una empresa, destinada a satisfacer el interés general de los asociados y la cual tiene funciones especializadas para operar cabalmente.

Estas funciones especializadas son lo que se conoció en algún momento como ramas del poder público, con base en la división de poderes acuñada por el francés Montesquieu (1942) y que inicialmente eran tres: la rama ejecutiva, judicial y legislativa. En la actualidad, y debido al abandono de la concepción simplista del Estado, por cuanto el constitucionalismo moderno lo concibe como algo complejo, y por otro lado el refinamiento de la teoría constitucional (Quinche, 2009, p. 433), 
para el caso colombiano, se transformaron en funciones públicas, que además de las tres funciones mencionadas, incluyeron la función de control, la electoral y la de banca central, de acuerdo con lo señalado por la Carta Política de 1991.

Cada función tiene una finalidad concreta, así, la función ejecutiva es por excelencia, como lo dice Ibáñez (2006, p. 222) a "que concentra mayor vínculo de acciones para lograr la realización de los fines del Estado, pues a su cargo está principalmente el ejercicio de la función administrativa". Alrededor de esta función confluyen dos conceptos perentorios, como son el de gobierno y el de administración. El gobierno, por un lado, se relaciona con la estructura política del Estado, es decir, la organización del poder político destinado a la consecución de efectos sociales, y por otra parte, la administración (Quinche, 2009, p. 438) que refiere, tal como lo interpreta la Corte Constitucional (Sentencia C-195 de 1994), a la ordenación técnica de los recursos del Estado con el fin de conformar un orden adecuado a las circunstancias y subordinado a los criterios políticos.

De acuerdo con lo anterior, Colombia ha sido organizada administrativamente de forma descentralizada, es decir, que otorga facultades o competencias administrativas a entidades públicas diferentes al Estado, para que las ejerzan en su nombre y bajo su responsabilidad (Rodríguez, 2007, p. 63), con el fin de dar cumplimiento a los fines del Estado. Este fenómeno está dado en tres formas: a) la descentralización territorial, que es el otorgamiento de competencias administrativas a las entidades territoriales; b) la descentralización especializada o por servicios, que otorga facultades administrativas a entidades que se crean para ejercer una actividad especializada, y c) la descentralización por colaboración, que otorga las competencias administrativas a particulares.

Todas las entidades antes descritas son personas jurídicas de derecho público, por tanto, tienen capacidad jurídica, lo que implica que sean titulares de derechos y obligaciones y que tengan la posibilidad, la aptitud y la idoneidad para ser titulares de relaciones jurídicas (Delgado, 2000), con el agravante de que sus decisiones trascienden del carácter personal al tener eco de la voluntad del Estado, y así sus actuaciones deben estar regidas por el conocimiento de la ley, lo que hace imperioso que en el desarrollo de sus funciones o competencias exista el asesoramiento jurídico que solo un profesional en derecho puede hacer.

La función judicial se encuentra definida en el Artículo $1^{\circ}$ de la Ley 270 de 1996 , estatutaria de la administración de justicia, como la que cumple el Estado por mandato de la Constitución y la ley para hacer efectivos los derechos, obligaciones, garantías y libertades consagradas en ellas. Dentro de esta función del Estado, además de la administración de justicia, se encarga de lo atinente al ejercicio de la 
profesión del abogado, teniendo como organismo especializado el Consejo Superior de la Judicatura. En esta parte del poder público, el ejercicio profesional del abogado se encuentra estrechamente ligado, ya que además de involucrarse al acudir a las instancias judiciales para exigir derechos de sus representados, el abogado hace parte de la formación de los propios despachos judiciales, siendo requisito que los propios jueces que toman las decisiones y sus subalternos sean abogados por regla general o tengan conocimientos en derecho de manera excepcional.

La función legislativa del Estado la ejerce el Congreso de la República, de la cual se cree popularmente que sus funciones se limitan a hacer leyes, sin embargo, a tenor literal del Artículo 114, como fundamento constitucional se avizora que tiene otras funciones, como por ejemplo la de control político. Por lo anterior, requiere, al igual que otras entidades, asesoría y defensa jurídica, por lo cual se justifica la vinculación laboral de profesionales en derecho.

El control, entre las funciones del Estado, es un principio que evita la concentración de poderes, ejercido entre ellas mismas para garantizar la democracia y la libertad de los ciudadanos (Quinche, 2009, p. 440); sin embargo, dentro de la estructura del Estado existe una función especializada para tal fin, justificada en el Artículo 117 de la Constitución Nacional. Como parte de esta función del Estado se encuentran dos organismos, el Ministerio Público y la Contraloría General de la República. Esta última tiene como fundamento constitucional el Artículo 119, encargándole la vigilancia y control de resultados de la administración y la gestión fiscal, y el Ministerio Público tiene fundamento en el Artículo 118 y lo conforman la Procuraduría General de la Nación, sus delegados y agentes, la Defensoría del Pueblo, los personeros municipales y demás funcionarios que determine la ley. Entre las funciones de este último están las de control, defensa de los derechos humanos y la función disciplinaria.

En la organización de las entidades mencionadas, tal como se ha insistido, su funcionamiento como entidades públicas requiere de abogados que aseguren su defensa y asesoría, al igual que las demás funciones del Estado, lo que implica que el jurista también pueda hacer parte de la nómina de empleados de estas entidades.

El Artículo 120 de la Constitución se ocupa de la función electoral, que es una organización conformada básicamente por el Consejo Nacional Electoral y la Registraduría Nacional del Estado Civil, que se encargan de las elecciones, su dirección y vigilancia. Debido a sus funciones, y con el fin de atender su funcionamiento, los abogados también hacen parte de los empleados que las integran, quienes serán los encargados de atender los derechos de petición, resolver 
los temas de contratación en general y defender o demandar en el evento de acciones judiciales.

Finalmente, el poder de la banca central que se encuentra en cabeza del Banco de la República, que es un organismo especializado y autónomo, tiene carácter de persona jurídica de derecho público (Ibáñez, 2006, p. 293) que tiene como directriz la política económica general y las funciones de banca central. Por lo anterior, allí también se debe contar con profesionales en derecho que asesoren y colaboren con la defensa y representación judicial.

Una vez señalada la incidencia del profesional del derecho en el ámbito de la administración pública, y de haber establecido su vinculación en cada una de las funciones del Estado, se da paso a la presentación de las condiciones en las que se encuentran vinculados laboralmente los profesionales del área jurídica a la administración del Estado. Para tal fin se presentará la función pública, como régimen general aplicable al personal de la administración (De Laubadère, citado por Rodríguez, 2007, p. 219), el tipo de vinculaciones, el régimen jurídico y las clases de empleados públicos, con el fin de excluir aquellos que no son destinatarios del régimen disciplinario general, como tema estructurante del presente artículo.

\subsection{El empleo público y el servidor público}

\subsubsection{La función pública}

La función pública es un concepto tan amplio, que engloba tres perspectivas: a) la general, que refiere a las actividades que se encuentran exclusivamente en cabeza del Estado; b) la del recurso humano, en cuanto relacionada con las acciones desempeñadas por los funcionarios públicos, los cuales representan el Estado; y c) de relación laboral, que se encuentra en el ámbito de relaciones laborales entre el Estado y sus servidores (Corte Constitucional, Sentencia C-113 de 1993).

Teniendo en cuenta estas precisiones, la función pública hace alusión a la acción desplegada o cumplida por una persona natural en virtud de su relación laboral con el Estado, y a través de la cual manifiesta de forma directa o indirecta la voluntad de la administración, que siempre deberá ser el logro del bienestar de la sociedad (fines del Estado), por lo cual están al servicio de los ciudadanos y del Estado, lo que implica que tanto su vinculación como su ejercicio laboral están provistos de solemnidades y de un régimen jurídico especial. En virtud de lo anterior, la función pública no solo es tomada en su alcance formal, sino que también es vista con un criterio finalista; así, además de las funciones que los servidores públicos deben 
cumplir de acuerdo con la Constitución y la ley, se tienen en cuenta los resultados y el impacto obtenido con la ejecución de las mismas.

Por regla general, los cargos en la administración se deben proveer a través de carrera administrativa, la cual se encuentra definida por el Artículo 27 de la Ley 909 de 2004 como "un sistema técnico de administración de personal que tiene por objeto garantizar la eficiencia de la administración pública y ofrecer; estabilidad e igualdad de oportunidades para el acceso y el ascenso al servicio público". En conclusión, la elección de los cargos se hace mediante proceso de selección, con excepción de aquellos servidores elegidos popularmente, los de libre nombramiento y remoción y los trabajadores oficiales, limitación señalada en el Artículo 125 de la Constitución Política.

Como se puede observar, es tan importante el ejercicio de un cargo público que además de ser destinatarios de obedecer la Constitución y la ley, los servidores públicos deben observar conductas de rectitud y probidad en el ejercicio de sus funciones, o de lo contrario, además de las responsabilidades a que haya lugar como ciudadanos del común, pueden ser destinatarios de una sanción disciplinaria en virtud del Código Disciplinario Único, el cual se encuentra plasmado en la Ley 734 de 2002, y que a efectos del presente trabajo se ha denominado régimen general disciplinario, y del que se hablará en detalle más adelante.

Solo resta destacar que para los profesionales en derecho que hagan parte de la administración pública, ejerciendo como abogados para alguna de las funciones del Estado, se deberá observar, al igual que los demás servidores, toda la normatividad anteriormente destacada, incluyendo el Código Disciplinario Único.

\subsubsection{Tipos de vinculación con el Estado}

De lo dicho en lo corrido del artículo se ha referido a servidores públicos como las personas que se encuentran vinculadas laboralmente al Estado en algunas de sus órdenes, ya sea central o descentralizado y en cualquiera de las funciones del Estado; sin embargo, este conjunto es el género, del cual hacen parte varias especies, que se identifican dependiendo de su vinculación. Estas llamadas especies se pueden determinar en miembros de las corporaciones públicas, empleados públicos, trabajadores oficiales y ocasionalmente los contratistas de la administración, los miembros de juntas, consejos y comisiones y los auxiliares de la administración.

Los miembros de las corporaciones públicas se caracterizan por ser de elección popular, para periodos predefinidos y fijos y tienen un régimen propio, dependiendo del orden al que pertenezcan. 
En los empleados públicos existe una subclasificación que obedece al criterio de naturaleza de la actividad y que se encuentra en el Artículo $1^{\circ}$ de la Ley 909 de 2004, el cual señala que los empleados públicos pueden ser de periodos fijos, de libre nombramiento o remoción y empleos temporales.

Los trabajadores oficiales, por otro lado, serán los encargados de la construcción, mantenimiento y sostenimiento de obras públicas en los ministerios, departamentos administrativos, superintendencias, unidades administrativas especiales, entidades territoriales en general y establecimientos públicos, y además los empleados de las empresas industriales y comerciales del Estado y de economía mixta que tengan capital público inferior al noventa por ciento $(90 \%)$, diferentes en ambos casos, a quienes ejercen funciones de dirección, confianza y manejo, quienes sí tendrán calidad de empleados públicos. De este grupo de trabajadores, la principal característica es que su vinculación con la administración se encuentra supeditada a un contrato de trabajo, similar al de un trabajador del sector privado, por lo cual se configura una relación de carácter contractual laboral.

De la clasificación dada anteriormente se tiene que al establecer la diferenciación entre cada grupo de trabajadores, el régimen jurídico aplicable para cada tipo de empleados varía, lo que explica que estando cerca de las entidades públicas se maneje un régimen jurídico particular para cada categoría. Sin embargo, como se puede observar, hay una clara diferenciación en cuanto al régimen legal asignado para los servidores públicos, ya que existen normas que se utilizan uniformemente para los servidores de todas las categorías, entre estas, se tiene el régimen unificado disciplinario, Ley 734 de 2002, dentro del ámbito del derecho disciplinario y que se expondrá a continuación.

\section{El régimen discipinario del servidor púbico y el régimen disciplinario del abogado}

\subsection{El “ius puniendi”}

Antes de comenzar a revisar las normas disciplinarias, es pertinente recordar la función sancionadora del Estado, como justificación del derecho disciplinario para los servidores públicos. Así las cosas, cabe resaltar que el ius puniendi es la expresión latina que explica la naturaleza del derecho penal y del derecho disciplinario dentro de la función del Estado, orientada al castigo de las conductas que más lesionan los intereses de la comunidad que designa o explica claramente la naturaleza. Esta función es quizás la más represiva del derecho público, como quiera que pone de manifiesto la capacidad del Estado para intervenir de manera contundente en la vida de los asociados (Millagón, s.f.). 
En concreto, en el derecho disciplinario, el derecho sancionador de la administración se materializa en la facultad que se le atribuye a los entes públicos de imponer sanciones a sus propios funcionarios buscando, como se dijo, particularmente asegurar el cumplimiento del orden jurídico, entre el que se encuentra la observancia de los principios que regulan el ejercicio de la función pública, como lo son los de igualdad, moralidad, eficacia, economía, celeridad, imparcialidad y publicidad (Artículo 209 de la Constitución Nacional).

Para tal fin, el derecho disciplinario se sirve de normas como la Ley 734 de 2002, que fija los deberes y obligaciones de quienes lo integran, limita el alcance de sus derechos y funciones, consagra prohibiciones y prevé un estricto régimen de inhabilidades, incompatibilidades, impedimentos y conflictos de intereses que, al ser desconocidos, abre la puerta a la falta disciplinaria, dando lugar en consecuencia a sus correspondientes sanciones y a los procedimientos constituidos para aplicarlas, lo cual implica que, a su vez, deban observarse las reglas y principios limitadores del ius puniendi establecidos para el derecho penal, como son, entre otros, el de legalidad y seguridad jurídica (Echano, 2000, pp. 61-63).

\subsection{Régimen discipinario general de los servidores públicos (Ley 734 de 2002)}

Ahora bien, en cuanto al régimen disciplinario general de los servidores públicos establecido en la Ley 734 de 2002, tal como lo ha definido la Corte Constitucional,

la acción disciplinaria se produce dentro de la relación de subordinación que existe entre el funcionario y la Administración en el ámbito de la Función Pública y se origina en el cumplimiento de un deber o de una prohibición, la omisión o extralimitación en el ejercicio de las funciones, la violación del régimen de inhabilidades e incompatibilidades, etc. y su finalidad es la de garantizar el buen funcionamiento, moralidad y prestigio del organismo público respectivo (Sentencia C-244 de 1996).

Es necesario señalar que uno de los órganos que ejercen la potestad disciplinaria es el Consejo Superior de la Judicatura, que es competente para conocer hasta la terminación del proceso de las faltas atribuidas a los funcionarios de la rama judicial, salvo de quienes tengan fuero constitucional.

De conformidad con lo dispuesto por el Artículo 25 de la Ley 734 de 2002, son destinatarios de la ley disciplinaria los servidores públicos, aunque se encuentren retirados del servicio, siempre y cuando la conducta se haya cometido al momento de estar vinculado a la administración, y los particulares que cumplan labores de interventoría en los contratos estatales, quienes ejerzan funciones públicas (solo en 
lo que tenga que ver con estas) o que presten servicios públicos a cargo del Estado, salvo las empresas de economía mixta que se rijan por el régimen privado (Artículo 53 del Libro Tercero).

En este punto se resalta que el abogado que ejerce su profesión dentro de la organización del Estado, es destinatario del Código Único Disciplinario, obedeciendo al criterio orgánico, es decir, que la aplicación del derecho disciplinario surge a partir del ejercicio del vínculo y no de la función, por el hecho de ser servidor público, en razón de su investidura, pues es titular genérico de las funciones públicas que implica su cargo, con independencia de si las ejerce o no. Contrario a ello, el particular que ejerce funciones públicas se hace destinatario de la ley disciplinaria en razón al criterio material; es decir, que al no tener un vínculo de subordinación o de dependencia con el Estado, en cualquiera de los cargos, organismos, entidades o corporaciones que hacen parte de su estructura, su responsabilidad se funda "en un factor objetivo y material: el ejercicio de la función pública que le ha sido confiada, pues este ejercicio afecta el interés público y, en esa medida, supera el ámbito del derecho privado" (Corte Constitucional, Sentencia C-286 de 1996).

Una vez revisada la Ley 734 de 2002, como la norma disciplinaria de los servidores públicos, se dará paso a la presentación de la ley disciplinaria de los abogados, la Ley 1123 de 2007, como norma rectora dentro del régimen disciplinario de los abogados, que busca la actualización de normas sustanciales y el mejoramiento del procedimiento, la celeridad y una mayor cobertura (Hernández, 2008), respecto del Decreto 196 de 1971 "Estatuto del Abogado".

\subsection{Régimen disciplinario del abogado}

La acción disciplinaria dentro del régimen de la Ley 1123 de 2007 se configura como la potestad del Estado de investigar y sancionar las faltas que cometen los abogados en ejercicio, a través de las Salas Jurisdiccionales Disciplinarias de los Consejos Superior y Seccionales de la Judicatura (Artículo 2 de la Ley 1123 de 1971). La acción disciplinaria, según esta misma norma, es independiente de cualquier otra que pueda surgir de la comisión de la falta.

La Corte Constitucional ha resaltado frente a este poder disciplinario, que este constituye una expresión de la función de vigilancia y control del Estado, en una profesión que requiere un ejercicio acorde con el interés general, interpretado a la luz de los valores y los principios constitucionales, en el entendido de que la profesión del abogado se orienta a concretar importantes fines constitucionales. En este sentido, el control y la vigilancia a través de la regulación legislativa son indispensables para el ejercicio adecuado de la profesión y en consecuencia para 
hacer efectivos diversos derechos fundamentales de los ciudadanos, como son la honra, la intimidad, el buen nombre, el derecho de petición, el derecho a la defensa $\mathrm{y}$, especialmente, el acceso a la administración de justicia (Corte Constitucional, Sentencia C-884 de 2007).

El Artículo 19 de la Ley 1123 de 2007 señala los destinatarios de la norma, los cuales son los abogados que en ejercicio de su profesión asesoren, patrocinen y asistan a las personas naturales o jurídicas de derecho público o privado, en la relación o desenvolvimiento de sus relaciones jurídicas, así se encuentren excluidos o suspendidos del ejercicio de la profesión y quienes actúen con licencia provisional. En este punto señala la norma que, bajo este régimen disciplinario, se encuentran amparados los abogados que desempeñan funciones públicas relacionadas con dicho ejercicio; es decir, los servidores públicos. También los curadores ad litem, al igual que los abogados que a través de un contrato de prestación de servicios profesionales proporcionen servicios a cualquier título (Artículo 19).

Los regímenes anteriormente presentados claramente exhiben similitudes en muchos de sus apartes normativos, lo cual puede tener no solo justificación en la materia que ambas regulan, sino que además se presume que la Ley 1123 de 2007, por ser posterior a la Ley 734 de 2002, retoma muchos de sus elementos, lo cual es verificable en la manera como están redactados los artículos.

En todo caso, frente a sus diferencias, las normas presentan características particulares que se clasificarán y se explicarán en la Tabla 1, que a continuación se muestra:

Tabla 1. Diferencias entre Ley 734 de 2002 y Ley 1123 de 2007

\begin{tabular}{|c|c|}
\hline \multicolumn{2}{|c|}{ FUNDAMENTO NORMATIVO } \\
\hline Ley 734 de 2002 & Ley 1123 de 2007 \\
\hline \multicolumn{2}{|c|}{ ÓRGANOS COMPETENTES } \\
\hline $\begin{array}{l}\text { Procuraduría General de la Nación, Ministerio } \\
\text { Público y Oficinas de Control Interno. }\end{array}$ & $\begin{array}{c}\text { Consejo Superior de la Judicatura y Consejos } \\
\text { Seccionales de la Judicatura. }\end{array}$ \\
\hline \multicolumn{2}{|c|}{ PROCEDIMIENTO } \\
\hline $\begin{array}{l}\text { Existen tres tipos de procedimiento: el } \\
\text { ordinario, el verbal y el especial ante el } \\
\text { procurador. De manera general, tiene más } \\
\text { etapas respecto del otro régimen, y el } \\
\text { proceso, tal como se encuentra diseñado en } \\
\text { la norma, es más minucioso. }\end{array}$ & $\begin{array}{l}\text { Hay un único tipo de procedimiento, tiene } \\
\text { menos etapas respecto del otro régimen y } \\
\text { el tratamiento del proceso es más general } \\
\text { dentro de su regulación normativa. }\end{array}$ \\
\hline
\end{tabular}




\begin{tabular}{|c|c|}
\hline \multicolumn{2}{|c|}{ FALTAS } \\
\hline $\begin{array}{l}\text { Las faltas tienen fundamento en el } \\
\text { incumplimiento de los deberes del servidor } \\
\text { público, referentes a los fines del Estado. } \\
\text { Esto cobija a quienes ejercen como abogados } \\
\text { pero al servicio de la administración. }\end{array}$ & $\begin{array}{l}\text { Las faltas tienen fundamento en el ejercicio } \\
\text { de la profesión, en el entendido de que } \\
\text { esta sirve como medio para garantizar } \\
\text { los derechos fundamentales de los } \\
\text { conciudadanos y su ejercicio incorrecto trae } \\
\text { consigo problemas de orden público. }\end{array}$ \\
\hline \multicolumn{2}{|c|}{ SANCIONES } \\
\hline $\begin{array}{l}\text { Este régimen tiene sanciones como retiro } \\
\text { del servicio, inhabilidad para trabajar, } \\
\text { suspensión, multa y amonestación escrita. }\end{array}$ & $\begin{array}{c}\text { Este régimen tiene sanciones como censura } \\
\text { pública, multa, suspensión y exclusión de la } \\
\text { profesión. }\end{array}$ \\
\hline
\end{tabular}

\section{El principio del "non bis in idem" y el régimen disciplinario del abogado al servicio de la administración pública}

\subsection{El principio del "non bis in idem"}

En el presente artículo se busca establecer cuál es el régimen aplicable a los abogados que son parte de la administración como servidores públicos, para así determinar si el principio del non bis in idem que se presenta a continuación se vulnera o no.

El principio del non bis in idem es conocido principalmente de la doctrina italiana y alemana y extraído del derecho romano, que significa que "nadie puede ser juzgado ni castigado dos veces por el mismo hecho". Su traducción literal es "no dos veces por el mismo hecho" (López 2004). Este principio general del derecho tiene su base en los principios de proporcionalidad y respeto a la cosa juzgada, y prohíbe la aplicación de dos o más sanciones o el desarrollo de dos o más procesos en uno o más órdenes jurídicos sancionadores, cuando se dé identidad de sujetos, hechos y fundamento y de acción (Del Rey, 1981).

El objetivo de este principio es la seguridad y la certeza de que el hecho por el cual ha sido sancionada o procesada una persona no sea revisado de nuevo por el Estado, en dos o más procesos, en el mismo proceso o en un futuro y dentro de una misma jurisdicción (León, 1998). Sin embargo, vale aclarar que lo anteriormente dicho sobre este principio no impide que un administrado sea sancionado por un mismo hecho con sanciones diversas, cuando cada una de ellas tenga una finalidad distinta, ya que como lo ha dicho la Corte Constitucional (Sentencia C-018 de 2004) lo que se proscribe es el doble proceso y no la doble sanción.

Empero, vale decir que el principio se torna relativo, pues además de que una doble sanción en el mismo fallo no sea una vulneración al principio, tampoco se proscribe la doble sanción cuando un hecho genera dos sanciones en diferente jurisdicción, 
como es el caso de la acción penal y la acción disciplinaria. En este punto aclaró la Corte Constitucional que "Siendo la acción disciplinaria distinta de la penal, cada una puede adelantarse en forma independiente, sin que su coexistencia se pueda deducir violación al principio del non bis in idem" (Sentencia C-948 de 2002).

\subsection{Aspectos jurisprudenciales del régimen aplicable a los servidores públicos que ejercen como abogados}

Dentro del estudio de fallos jurisprudenciales se encuentran unos para destacar, como la Sentencia C-899 de 2011, ya que esta, en sede de acción de inconstitucionalidad, estudia el inciso 2 (parcial) del Artículo 19 de la Ley 1123 de 2007, que señala los destinatarios de este régimen disciplinario. Uno de los cargos se formula en la transgresión del principio constitucional del non bis in idem, que se encuentra contenido en el Artículo 29 de la Constitución Nacional, que prohíbe el doble juzgamiento, ya que se puede entender que los abogados con funciones públicas pueden ser investigados disciplinariamente bajo el régimen de la Ley 1123 de 2007, si incumplen un deber profesional, y también por el contemplado en la Ley 734 de 2002 por incumplir un deber funcional.

La dogmática del derecho disciplinario señala que se sanciona la infracción al deber funcional, con el fin de que se cumplan los postulados de la función pública y corregir las conductas de quienes la ejercen, para que el Estado pueda cumplir su cometido, conforme a los fines consagrados en el Artículo 2 de la Constitución Política. Por lo anterior, la infracción del deber funcional pone en peligro la función pública y justifica así la competencia para investigar e imponer sanciones disciplinarias por parte de la Procuraduría y en contra de los servidores públicos.

Ahora bien, el análisis de la Corte sigue en línea en cuanto al derecho disciplinario frente a las profesiones, recordando que el Artículo 26 de la Constitución garantiza, por una parte, la libertad de escoger profesión u oficio, y por otra, la facultad del Estado de inspeccionar y vigilar su ejercicio, como la de exigir títulos de idoneidad. Esa facultad de inspección y vigilancia tiene su principal fundamento en el riesgo social que representa para la sociedad el ejercicio de las profesiones y de ciertos oficios (Corte Constitucional, Sentencia C-568 de 2010). En este sentido, la misma Corte Constitucional en Sentencia C-530 de 2000 afirmó que:

es acorde con el Art. 26 de la Constitución, que atribuye a las autoridades competencia para inspeccionar y vigilar el ejercicio de las profesiones, con el fin de prevenir la ocurrencia de riesgos sociales; en tal virtud, para cumplir con este cometido le corresponde al legislador determinar la composición y señalar las funciones de los órganos encargados del control disciplinario, para 
asegurar que el ejercicio de la respectiva profesión se cumplan dentro de ciertos parámetros éticos y de eficiencia, eficacia y responsabilidad, acordes con el interés general que demanda la prevención de los aludidos riesgos.

Lo cual hace coherente que la competencia para imponer dichas sanciones pueda ser ejercida directamente por un órgano estatal, como sucede en el caso de la profesión de abogado, que fue asignada directamente por el constituyente a los consejos Seccional y Superior de la Judicatura (Artículo 256 numeral 3 de la Constitución Política).

Precisa la Corte, que la prohibición del non bis in idem comprende todos los campos en los cuales se ejerce el ius puniendi del Estado, consecuencia del mandato expreso del Artículo 29, que irradia el ámbito de los procesos penales y administrativos, lo cual implica que su cubrimiento va desde el campo penal hasta el derecho sancionatorio administrativo en lo disciplinario, fiscal, policivo, correccional, entre otros (Sentencia C-554 de 2001).

En consecuencia, la prohibición del principio que hoy se menciona, y que contiene el Artículo 29 constitucional, según la corporación, se debe analizar en relación con actuaciones estatales de la misma naturaleza y finalidad, sin que sea posible afirmar su desconocimiento cuando se trate de procedimientos regidos por normativas con un contenido y objeto diferentes, porque ello sería someter las competencias de distintos órganos del Estado a la actuación de aquel que primero inicie o produzca un resultado concreto frente al sujeto investigado.

Una vez analizado lo anterior, la Corte comienza a resolver los cargos, concluyendo que, le corresponde al procurador general, en los términos del Artículo 277 numeral 6 de la Constitución, adelantar las investigaciones e imponer las sanciones a quienes desempeñen funciones públicas, salvo las excepciones consagradas en la misma Constitución. Por tanto, cuando un servidor público, en los términos del Artículo 123 constitucional, o un particular, incurren en una infracción a su deber funcional, corresponde al procurador general o a la oficina de control interno disciplinario, según sea el caso, hacer uso de su facultad disciplinaria para investigar y sancionar la respectiva falta, independiente de la profesión que ostente el servidor o el particular concernido.

Por otra parte, para la Sala, el Artículo 19 de la Ley 1123 de 2007 está planteando que todos los abogados que cumplan con la misión de asesorar, patrocinar y asistir a las personas naturales o jurídicas, tanto de derecho privado como de derecho público, son sujetos pasibles de este estatuto. El inciso segundo aclara que se entienden incluidos en dicho régimen los abogados que tengan una relación subjetiva con 
el Estado, como servidores públicos o particulares en ejercicio de una función administrativa en lo que hace al ejercicio de su profesión, es decir, cuando el objeto de la vinculación con el Estado sea, precisamente, el de asesorar, patrocinar y asistir a una entidad estatal en el desarrollo de la función asignada.

Destaca la Sala, que el inciso acusado se debe interpretar en cuanto los abogados que en su condición de servidores o particulares que ejerzan función pública deban ejercer la profesión, por lo que quedan sujetos al Código Disciplinario del Abogado por las faltas que lleguen a cometer en su ejercicio, sin que ello excluya la competencia de los órganos disciplinarios encargados de velar por el correcto ejercicio de la función pública en los términos de la Ley 734 de 2002, ya que los órganos competentes asignados por cada normatividad tienen una naturaleza distinta.

En conclusión, la facultad que tienen los consejos Seccional y Superior de la Judicatura para investigar y sancionar a los abogados que desarrollen la profesión en ejercicio del vínculo con el Estado, no desconoce ni la competencia de la Procuraduría General de la Nación ni la prohibición de ser juzgado dos veces por el mismo hecho, porque la competencia del procurador general se mantiene incólume para investigar y juzgar a los servidores y particulares que ejercen función pública por la infracción del deber funcional, independientemente de la profesión que ostenten.

\subsection{Aplicación de los presupuestos del "non bis in idem" a los sujetos destinatarios simultáneamente de las leyes 734 de 2002 y 1123 de 2007}

De acuerdo con las reflexiones que se han hecho a lo largo del presente artículo, se procede a analizar los presupuestos que permiten determinar si existe transgresión al principio del non bis in idem. En primer término se va a determinar si los procedimientos en conflicto, o como en el presente caso, las normas analizadas, hacen parte del derecho punitivo, es decir, los campos en los cuales se ejerce el ius puniendi del Estado, lo que cubre desde el campo penal, hasta el derecho sancionatorio administrativo en lo disciplinario, fiscal, policivo, correccional, entre otros. En este sentido, las normas en mención hacen parte efectivamente del universo del derecho sancionador, ya que estas se dirigen a sancionar las conductas que sean contrarias a los principios de la función pública y a los del ejercicio de la profesión del abogado, respectivamente, lo que implica que la sanción sea una consecuencia inmediata de la falta. Lo anterior conduce a que se dé cumplimiento al primer presupuesto y supone, entonces, la verificación del segundo presupuesto, que tiene lugar con la identidad de sujeto, objeto y hecho, como a continuación se analizará.

Teniendo en cuenta lo señalado en los presupuestos para la configuración de la vulneración del principio que prohíbe el doble juzgamiento, se observa que la 
identidad del sujeto no se limita a la verificación del sujeto como individuo físico, sino que esta identidad se establece en el plano de lo jurídico, que implica que una misma persona pueda encarnar en sí una multiplicidad de sujetos frente al derecho. En este sentido, en el caso concreto del abogado que ejerce funciones públicas, este efectivamente comporta varias calidades, la primera será de ciudadano, la cual tiene una sujeción general con la administración, por ser precisamente un administrado; la segunda será en su calidad de servidor público, en virtud de la sujeción especial que lo vincula a la administración; y en tercer lugar la calidad de profesional del derecho.

De estas dos últimas calidades, cada una lo hace destinatario de la ley disciplinaria del servidor público y a su vez de la ley disciplinaria del abogado, sin que ello implique que exista una identidad de sujeto, aunque sea la misma persona, pues este sujeto se entiende desde el punto de vista de la calidad en la que incurre en la falta.

Frente a la identidad del objeto, tal como lo indica la doctrina del principio del doble juzgamiento, el objeto a que se refiere este presupuesto no es más que el bien jurídico que busca proteger las normatividades en conflicto.

Así las cosas, frente a los bienes jurídicos tutelados por la Ley 1123 de 2007, se tiene que acudir a los fines de la profesión del abogado, como es la función social que cumple este profesional, según los artículos primero y segundo del Decreto 196 de 1971, como complementarios de la ley disciplinaria del abogado, y que junto con las disposiciones de esta norma, dan lugar a que los deberes del abogado sean: observar la constitución y la ley (Artículo $1^{\circ}$ ), defender y promocionar los derechos humanos (Artículo $2^{\circ}$ ), colaborar en la realización de la justicia y los fines del Estado (Artículo $6^{\circ}$ ), prevenir litigios "innecesarios, innocuos o fraudulentos", facilitar los mecanismos de solución alternativa de conflictos (Artículo 13) y abstenerse de incurrir en actuaciones temerarias (Artículo 16). Lo anterior indica que la profesión adquiere una especial relevancia social, pues se encuentra íntimamente ligada a la búsqueda de un orden justo y al logro de la convivencia pacífica (Corte Constitucional, Sentencia C-290 de 2009.)

En el caso de la ley disciplinaria para los servidores públicos, el bien jurídico protegido, o su finalidad, es la protección y el correcto funcionamiento de la función pública, razón por la que el servidor vinculado con el Estado para ejercer su profesión a través del litigio, el asesoramiento y la representación, entre otros, debe responder por la violación del deber funcional en los términos de la regulación que rige la conducta de los servidores públicos (Ley 734 de 2002). Así las cosas, la disparidad en cuanto al ámbito de protección implica que tampoco se cumpla este presupuesto dentro de la vulneración del principio del doble enjuiciamiento. 
Por último, en cuanto a la identidad fáctica, esta corresponde al hecho generador de la activación de los sistemas sancionatorios, que, en el caso del derecho disciplinario, será la falta. Así las cosas, si bien es cierto que un hecho puede generar la activación de ambos sistemas sancionatorios, conforme la Ley 734 de 2002 y la Ley 1123 de 2007, será replicable que el hecho pueda dar lugar a la misma falta, ya que estas difieren en cada una de las normatividades, al igual que el tipo de sanción que corresponde y los criterios de su graduación, por lo cual un hecho propiamente no daría lugar a la misma falta. Ahora bien, también es dable el evento en el cual un mismo hecho no active ambos sistemas normativos, sino uno de los dos, a causa de la diferencia en la tutela de bienes jurídicos, lo cual consecuentemente da lugar a faltas distintas y estas, a su vez, a sanciones de diferente naturaleza. Por lo anterior tampoco se puede dar, en plenitud, la identidad fáctica para la consideración de la vulneración del principio del non bis in idem frente al sometimiento de la misma persona al Código Disciplinario Único y al Código Disciplinario de los Abogados.

\section{Conclusiones}

A partir de lo analizado en el presente artículo se concluye que dentro del derecho disciplinario administrativo se encuentra el régimen jurídico disciplinario aplicable a los servidores públicos, del que el abogado puede hacer parte, y que está normado en la Ley 734 de 2002, en la cual se hacen destinatarios quienes ejerzan funciones públicas, ya sean servidores o particulares con funciones transitorias. En este derecho disciplinario también se encuentra la Ley 1123 de 2007, que fundamenta el régimen disciplinario de los abogados.

Igualmente, la Ley 734 de 2002 busca sancionar las conductas que deformen la función pública, como el incumplimiento de deberes, abuso en el ejercicio de derechos, extralimitación de funciones, violación del régimen de prohibiciones, inhabilidades, impedimentos e incompatibilidades y conflicto de intereses consagrados en la Constitución o en la ley; mientras que la Ley 1123 de 2007 busca sancionar las conductas que afecten la dignidad de la profesión, traducidas en faltas contra la dignidad de la profesión, contra el decoro profesional, contra el respeto debido a la administración de justicia y a las autoridades administrativas, contra la recta y leal realización de la justicia y los fines del Estado, faltas de lealtad con el cliente, faltas a la honradez del abogado, faltas a la lealtad y honradez con los colegas, faltas a la debida diligencia profesional y faltas contra el deber de prevenir litigios y los mecanismos de solución alternativa de conflictos.

Por otra parte, el desarrollo jurisprudencial de la Corte Constitucional en Sentencia C-899 de 2011 permite inferir que efectivamente el abogado al servicio de la administración se encuentra sometido y es destinatario tanto de la Ley 734 de 2002 , 
como de la Ley 1123 de 2007, y como quiera que estas tienen una naturaleza distinta, no se vulnera el principio del non bis in idem.

Finalmente, la no vulneración del principio del non bis in idem radica en que no se configuran los presupuestos de este principio en la aplicación de los regímenes disciplinarios de la ley disciplinaria de los servidores públicos y las del abogado, a pesar de cumplirse el primer presupuesto, puesto que ambos procedimientos o regímenes se encuentren dentro del universo del ius puniendi, o derecho sancionador. Así mismo, no se da la identidad de sujeto en el plano jurídico, no existe una identidad de objeto, pues ambas leyes protegen bienes jurídicos distintos, ya que la ley disciplinaria de los servidores públicos protege la función pública como garantía de efectividad del cumplimiento de los fines del Estado y, en cambio, la ley disciplinaria del abogado protege el correcto y adecuado ejercicio de la profesión como garantía de los derechos fundamentales de las personas.

Por tal razón, a los profesionales en derecho al servicio de la administración les es aplicable tanto el Código Disciplinario del Abogado, Ley 1123 de 2007, como el Código Disciplinario Único, Ley 734 de 2002, como quiera que por sus condiciones especiales son destinatarios de ambas normas y de las sanciones correspondientes, sin que con ello se vulnere el principio del non bis in idem.

\section{Referencias}

Asamblea Nacional Constituyente (1991). Constitución Política de Colombia de 1991. Bogotá: Imprenta Nacional.

Bocanegra, H. (2012, enero-junio). La enseñanza del derecho y la formación de los abogados. Revista Republicana, (12), 323-347.

Congreso de la República de Colombia. (2007, 22 de enero). Ley 1123 de 2007. Por la cual se establece el Código Disciplinario del Abogado. Diario Oficial, (46.519).

Congreso de la República de Colombia. (2002, 5 de feb.). Ley 734 de 2002. Por la cual se expide el Código Disciplinario Único. Diario Oficial, (44699).

Corte Constitucional colombiana. (1993). Sentencia C-113 de 1993.

Corte Constitucional colombiana. (1994). Sentencia C-195 de 1994.

Corte Constitucional colombiana. (1996). Sentencia C-244 de 1996.

Corte Constitucional colombiana. (1996). Sentencia C-286 de 1996.

Corte Constitucional colombiana. (1996). Sentencia C-530 de 2000. 
Corte Constitucional colombiana. (2001). Sentencia C-554 de 2001.

Corte Constitucional colombiana. (2002). Sentencia C-948 de 2002.

Corte Constitucional colombiana. (2004). Sentencia C-018 de 2004.

Corte Constitucional colombiana. (2007). Sentencia C-884 de 2007.

Corte Constitucional colombiana. (2008). Sentencia C-290 de 2008.

Corte Constitucional colombiana. (2010). Sentencia C-568 de 2010.

Corte Constitucional colombiana. (2011). Sentencia C-899 de 2011.

Delgado, J. et al. (2000). Elementos del derecho civil: parte general del derecho civil. Vol. II. Madrid: Dykinson.

Del Rey, S. (1981). Potestad sancionadora de la administración y la jurisdicción penal en el orden social. Madrid: Ministerio de Trabajo y Seguridad Social.

Echano, J. (Coord.). (2000). Derecho penal. Parte general: Materiales didácticos. (3 ed.). Bilbao: Universidad de Deusto.

Gómez, H. (1974). Lo humano de la abogacía y de la justicia. Bogotá: Cosmos.

Hernández, M. (2008). El régimen disciplinario de los abogados. Revista Principia Iuris, 10.

León, F. (1998). Acumulaciones de sanciones penales y administrativas: sentido y alcance del principio non bis in idem. México: Bosch.

López, J. (2004). El principio non bis in idem. Madrid: Dykinson.

Martínez, L. (2004). Controles y Responsabilidades en el sector público. México: Plaza y Valdez.

Millagón, F. (s.f.). El ius puniendi, su eficiencia y los derechos fundamentales en el mundo contemporáneo. En E. Mora (Coord.). Uso legítimo de la fuerza. México: Instituto Nacional de Ciencias Penales.

Montesquieu, C. L. (1942). El espíritu de las leyes. N. Estevanez (trad.). Buenos Aires: Albatroz.

Pacheco, M. (s.f.). Teoría del derecho. (4 ed.). Santiago de Chile: Editorial Jurídica de Chile.

Pérez, R. (2004). Los abogados de América Latina, una introducción histórica. Bogotá: Universidad Externado de Colombia.

Quinche, M. F. (2009). Derecho constitucional colombiano de la Carta de 1991 y sus reformas. Bogotá: Editorial Universidad del Rosario. 
Rivero, J. (1984). Derecho administrativo. (Trad. $9^{a}$ ed.). Caracas: Instituto de Derecho Público, Universidad Central de Venezuela.

Rodríguez, L. (2007). Derecho administrativo general y colombiano. Bogotá: Temis.

Sánchez, J. (2001). La administración pública como ciencia. México: Plaza y Valdez.

Vedel, G. (1980). Derecho administrativo. (Trad. $6^{\text {a }}$ ed.). Madrid: Biblioteca Jurídica Aguilar. 